\title{
Hirsutism with rapid onset presenting in a 62-year-old postmenopausal woman
}

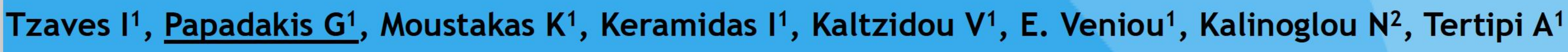

Department of Endocrinology (1) and Gynecology (2), Metaxa Anticancer Hospital, Pireaus, Greece

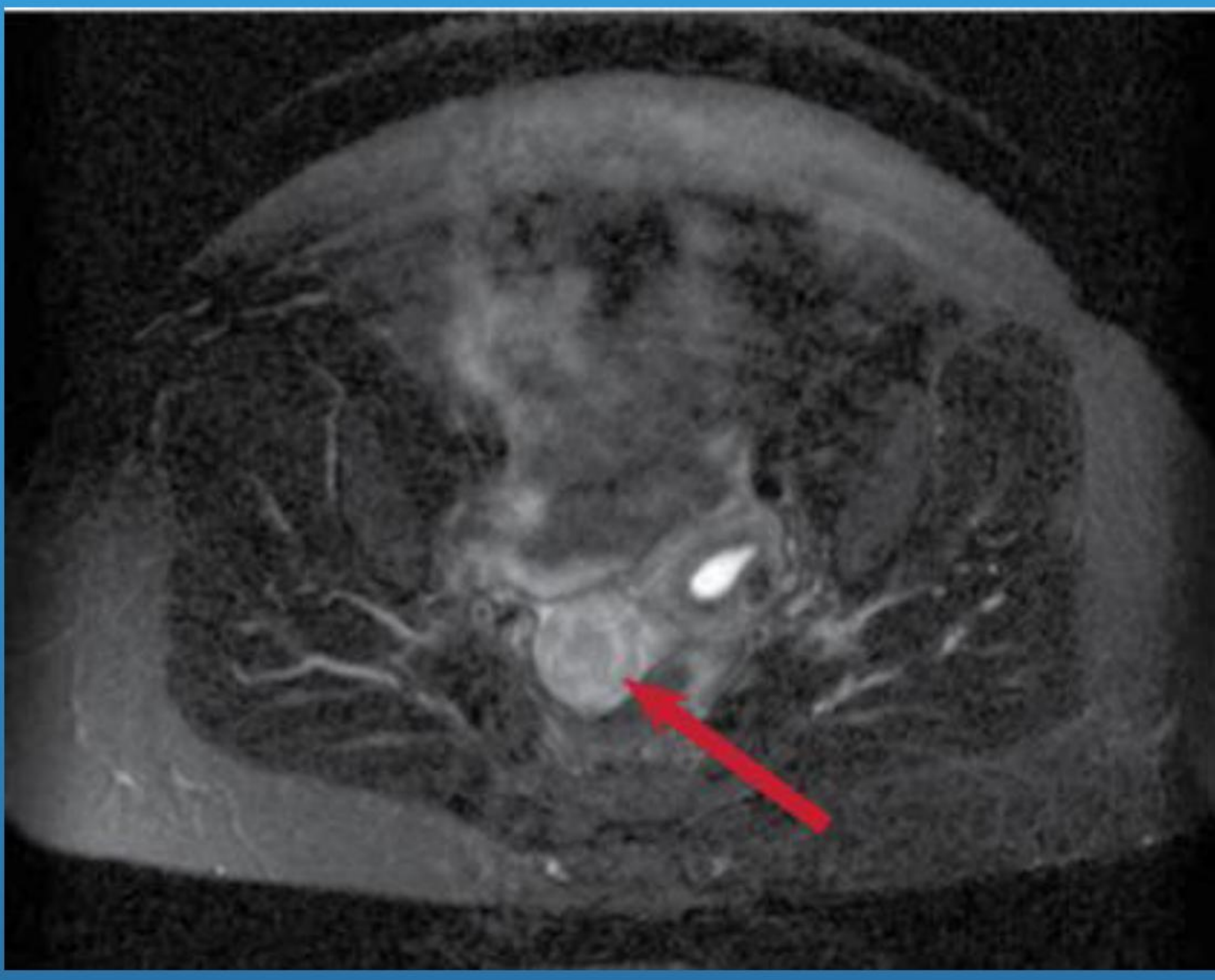

Figure 1: MRI of the right ovary

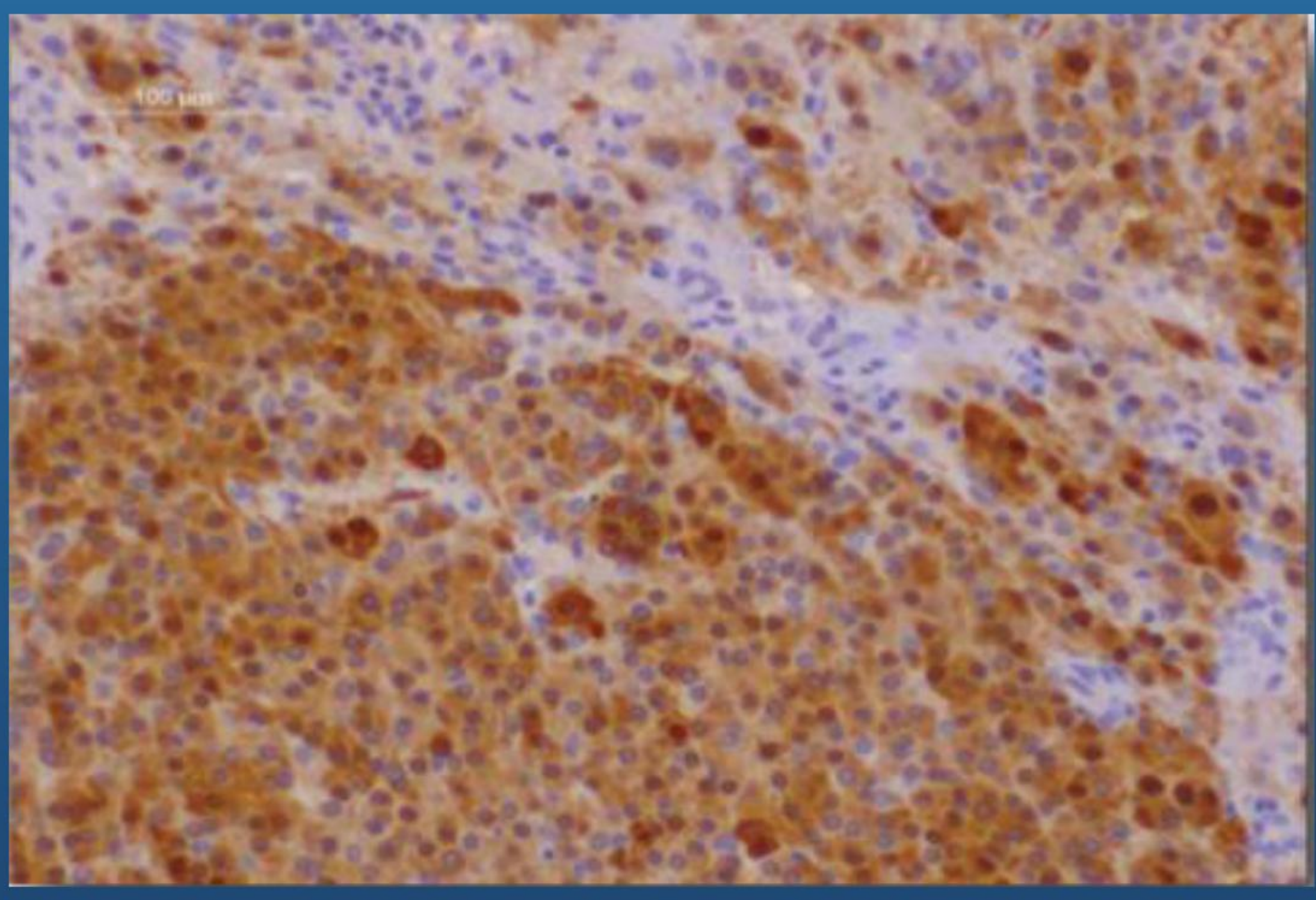

Figure 2. Calretinin immunohistochemistry of the tumour
Introduction: Virilizing tumors are rare, but frequent cause of virilization in postmenopausal women.

Case report: A 62-year-old postmenopausal woman presented with a rapid onset of hirsutism with increased terminal hair growth, particular on chin and abdomen, frontal male pattern balding in the last 5 months. Physical examination revealed a lowpitched, deepened voice and clitoromegaly. The Ferriman-Gallwey score was 18. Laboratory evaluation showed significant elevation of testosterone (Table 1 ).

\begin{tabular}{|l|l|l|}
\hline $\begin{array}{l}\text { Table } 1 . \\
\text { Hormone }\end{array}$ & Value & Normal range \\
\hline Testosterone $(\mathrm{ng} / \mathrm{ml})$ & 11.2 & $0.07-0.65$ \\
\hline DHEAS $(\mu \mathrm{g} / \mathrm{dl})$ & 154.4 & $24.6-182.3$ \\
$17(\mathrm{OH}) \mathrm{P}(\mathrm{ng} / \mathrm{ml})$ & 0.5 & $0.19-0.71$ \\
$\Delta 4 \mathrm{~A}(\mathrm{ng} / \mathrm{ml})$ & 1.4 & $0.3-3.7$ \\
\hline $\mathrm{FSH}(\mathrm{IU} / \mathrm{L})$ & 11.6 & $27.7-93.3$ \\
$\mathrm{LH}(\mathrm{IU} / \mathrm{L})$ & 1.6 & $14.4-52.8$ \\
$\mathrm{PRL}(\mathrm{ng} / \mathrm{ml})$ & 6 & $1.9-17.9$ \\
$\mathrm{E}_{2}(\mathrm{pg} / \mathrm{ml})$ & 91.7 & $6-53$
\end{tabular}

On a 48-h low-dose ( $2 \mathrm{mg} /$ day) dexamethasone-suppression test, testosterone showed only a $24 \%$ reduction from baseline, while DHEAS was practically unchanged. A pelvis MRI scanning revealed normal adrenal glands and enlargement of the right ovary with an echogenic solid mass measuring $3.6 \times 3.7 \times 4 \mathrm{~cm}$ (Figure 1) and a laparoscopic right salpingo-oophorectomy was performed. Histopathology revealed a Leydig cell tumor with no malignant features. Figure 2 shows a calretinin immunohistochemistry picture of the tumor.

\begin{tabular}{|l|r|r|r|r|}
\hline $\begin{array}{l}\text { Table 2. } \\
\text { Hormone }\end{array}$ & $\begin{array}{l}\text { Baseline } \\
\text { value }\end{array}$ & $\begin{array}{l}\text { After test } \\
\text { value }\end{array}$ & $\begin{array}{l}\text { Percentag } \\
\text { e change }\end{array}$ \\
\hline Testosterone $(0.07-0.65 \mathrm{ng} / \mathrm{ml})$ & 11.2 & 8.5 & $-24 \%$ \\
\hline DHEAS $(24.6-182.3 \mu \mathrm{g} / \mathrm{ml})$ & 154 & 149 & $(-)$ \\
\hline Cortisole $8 \mathrm{pm}(9.36-25.92 \mu \mathrm{g} / \mathrm{dl})$ & 17.1 & 1.6 & \\
\hline
\end{tabular}

Conclusions: Hyperandrogenism and especially virilization in menopausal women needs a thorough investigation since the percentage of virilizing tumors of adrenal or ovarian origin is much higher in menopause than during reproductive age. Ovarian virilizing tumors are usually benign and the treatment of choice is surgical removal. 